Administrative Issues Journal: Connecting Education, Practice, and Research, Winter 2016, Vol. 6, No. 2: 5-12. doi:10.5929/2016.6.2.8

\title{
Planning a Library Leadership Retreat on the Cheap: Case Study and Analysis
}

\author{
Stewart Brower, MLIS, AHIP \\ Director, Schusterman Library \\ University of Oklahoma-Tulsa
}

\begin{abstract}
Staying ahead of the pitch: an old baseball metaphor that means to anticipate where the ball is going to go so that the batter can score a hit. But to anticipate changes in a field as robust and challenging as information sciences, reflection and contemplation are often key to good planning. With simple day-to-day management of libraries already being a full-time task, true leadership and planning often comes with a real, physical break from the workplace and daily routines.

With this in mind, the leadership retreat should be employed by librarians to give themselves the luxury of deep reflection, camaraderie, and thoughtful planning in environments conducive to such work. This article outlines a simple process that can be used to run a planning retreat, at a reasonable cost, and within a modest time frame. To outline this process, a case study involving the University of Oklahoma-Tulsa Schusterman Library will be described.
\end{abstract}

Key words: library leadership retreat

T he Schusterman Library, a 22,000 square foot facility on the Tulsa campus of the University of Oklahoma, opened its doors for business in May 2011. This award-winning facility has several noteworthy features for a library of relatively small size, including a digital gallery space, student conference rooms, a large and inviting information commons, a quiet reading room, and compact mobile shelving for the physical collection. Additionally, the library has abundant natural light throughout the day, a large atrium featuring a curtain glass wall, comfortable furnishings, and color tones of white and dark gray throughout the building. The library is frequently featured in campus photography and is generally thought of as an attractive, welcoming space in which to study.

In the first few years of library operation, the Schusterman Library enjoyed significant gate counts as well as strong metrics in instruction, reference, and document delivery services. However, assessment figures from the 2013/14 school year compared with the 2014/15 school year showed a significant drop in all areas: instruction has decreased by one-quarter, reference statistics by one-sixth, and the overall gate count has dropped from $43 \mathrm{~K}$ to $37 \mathrm{~K}$, a decrease of nearly $15 \%$ in just one year. With student 
enrollment remaining mostly constant (approximately 1600 FTE), other factors must account for the decreases in these primary metrics.

The library director was made aware of these trends early in the summer of 2015, right after the 2014/15 numbers were compiled. The director and associate director conferred several times on the matter, and the decision was made in late summer to organize a library planning retreat for the early fall. With a brand new librarian hire and the typical crush of information literacy classes and new student orientations that comes in early fall, time to plan the retreat was minimal. Additionally, while the campus administration agreed that putting together the retreat was a good idea, funds for such planning were minimal. In summary, the librarians needed the retreat to come together quickly and without much cost.

Library planning is, in many respects, subject to the same concepts that drive any other planning. First, determine what your objectives for planning might be, then structure planning exercises and discussion about reaching those objectives. Next, move from planning to implementation followed by assessment, the results of which suggest adjustments and corrections to the original plan. Then the cycle starts all over again.

The more traditional form of "strategic planning" should fulfill this purpose, but unfortunately can lose its shape somewhere along the way. Perhaps library plans are rooted in the parent organization's tentpole goals for the next five years, but implementation is hampered by lack of resources or changes in administration. Or maybe the implementation is strong, but poor assessment techniques leave library leaders with muddied, unusable numbers that cannot guide future planning. Strategic planning is vital for any organization, but doing it well is exceptionally difficult, particularly without a mechanism for integrating such planning into the lifeblood of the organization (Matthews, 2005, pp. 83-92). Lastly, true strategic planning is usually costly. Consultants draw high dollars for guiding organizations through the planning process. Administrators consume large amounts of their work time attempting to keep planning on track in the organization. Line workers spend precious work hours reading confounding planning charts and documents, sitting through exhausting and often unusable training, and never fully understanding why the planning is important or what they are expected to do (Casey, 2015).

Retreats have often been viewed through a lens of team-building, morale-creating exercise-a human resources opportunity rather than an administrative planning one (Cluff \& Von Dran, 1988). Some library staff retreats have become an opportunity to engage in workplace improvement activity, including explorations of customer service and skill training, but with little actual planning (Gray, Brower, \& Munger, 2001). However, more recently the retreat is starting to be seen as an opportunity to engage in planning, often as a means to respond to change (Dobb, 1999; Kirkland \& Dobb, 1989).

Since 20111, the Schusterman Library has committed to an annual all-staff retreat, usually set around a specific theme that would benefit all employees. The first retreat, held in the summer of 2012, was an all-day look at the library's history, its services, and the financial outlook for the organization. The second all-staff retreat in 2013 focused on customer service and, at the end of the day, outlined approximately a dozen changes that would be rapidly implemented to remediate lapses of service. 
Largely, it addressed shortcomings between the library's two service points, as well as examining potential new services to offer and a checklist of basic activities for all public services staff.

In the end, both retreats suffered from a number of problems. With so many staff participating, some individual voices were drowned out, and participation was generally uneven. Additionally, both retreats were somewhat costly. Consultants were hired and brought in to help with planning and discussion. Catering and room rentals added to the expense. However, the biggest expense closing the library for a day, which meant that all the staff were being paid, but no actual library work was being done. Although scheduling retreats between semesters minimized the impact on our users, some disruption of library activities was unavoidable. Each retreat cost between $\$ 3,500$ and $\$ 4,000$, and the return on that investment was minimal.

The idea to move the retreat to include only the library leadership corrected several of these issues. The retreat itself could be made a little longer and include an overnight stay, which would be impossible for an all-staff event. For the leadership to retreat for a few days did not require closing the library, and a leadership retreat could be carried out for a fraction of the cost of an all-staff retreat. With a smaller group, pre-planning exercises could be conducted so that all retreaters would have access to material in advance. A smaller, experienced group would be able to work together more smoothly, without the intervention of a planning expert or other costly consultant. And, by bringing in only the library leadership team and keeping the group small, everyone was assured of playing a significant role in the planning process and of being heard.

\section{The Leadership Retreat}

Planning our first leadership retreat began with an examination of desired objectives. With the assessment figures for 2014/15 indicating such a dramatic drop-off, the objective came together fairly easily:

To come away from the retreat with plans to increase library attendance and to improve relationships with students, staff, and faculty.

Outcomes from that objective included event planning, library advisory planning, marketing and promotions planning, and assessment. Each outcome was assigned a team leader based on their individual responsibilities and job descriptions. Team leaders then prepared themselves and the group as follows:

- Advance preparation: Team leaders wrote sections for the planning document that were distributed in advance of the retreat. Each section included links to background readings and, whenever appropriate, assignments to be completed before the retreat.

- Open discussion: On the first day of the retreat, each team leader would conduct planning with the larger group for a period of one hour. On the second day, each team leader would get an additional half hour of time to refine or adjust the findings from the previous day. 
- Reflection: Between the first and second day of the retreat, unstructured time gave everyone an opportunity to reflect on the day's activities and discuss what we had learned.

- Action items: The morning of the second day was spent refining the first day's work. All team leaders were instructed to come away from the retreat with specific action items, prioritized and ranked, that could be acted on within the next year. Additionally, they were to record any ongoing or future action items that would need more time or resources before they could be enacted.

To better understand how this retreat came together, this case study will present an abbreviated breakdown of both days' activities.

\section{Leadership Retreat, Day Before}

3:00 p.m. Check-in - arrivals throughout the evening

5:00 p.m. Snacks and general discussion

7:00 p.m. Dinner

9:00 p.m. Dessert and general discussion

\section{Leadership Retreat, Day One}

8:30 a.m. Breakfast

9:30 a.m. Goal-setting and thoughts about the retreat-led by the library director, this brief session set the tone and explained the overall objectives of the retreat to all the participants, while opening the door to broader discussion.

10:00 a.m. Event planning - the team leader for event planning had conducted an all-staff survey to learn what kinds of events they would like to see in the library. The leadership team also brainstormed for a half-hour on possible events, and all the events were written out on post-it notes. As a team, we then arranged all the events into a chart measuring anticipated effort against expected attendance.

11:00 p.m. Library Advisory planning - the team leaders for advisory planning discussed the need for an advisory body, and led a broader discussion about library allies and champions around campus, as well as those who might have less-than-favorable expectations of the library.

12:00 noon Lunch

1:30 p.m. Marketing/Promotions planning-the marketing team leader showed the leadership team a ten-minute video she had filmed and edited of interviews with library non-users from around the campus, including their impressions of the library and its services. Armed with this new knowledge, the leadership team then conducted an exhaustive 
self-analysis of library services and resources, a look at everything the library potentially provides to the campus community.

2:30 p.m. Assessment planning-the assessment team leader shared and reflected on the last year's assessment data, giving specific attention to the areas where the library was experiencing significant losses, including gate counts, teaching opportunities, and mediated searches. This examination wrapped up with a discussion about what metrics were currently being measured and what metrics needed to be measured in the future. Additionally, the team was given the opportunity to suggest a "big question" that could be answered in the coming year.

3:30 p.m. Break for games/free time

4:30 p.m. General discussion, review

6:00 p.m. $\quad$ Appetizers \& drinks

7:00 p.m. Dinner

8:30 p.m. Desserts \& drinks

For the second morning, each team leader was allocated thirty minutes to reflect on the previous day's work and to deliver specific, prioritized action items for their section.

\section{Leadership Retreat, Day Two}

8:30 a.m. Breakfast

9:30 a.m. Event planning - Final priorities

10:00 a.m. Library Advisory planning - Final priorities

10:30 a.m. Marketing/Promotions planning - Final priorities

11:00 a.m. Assessment planning - Final priorities

11:30 a.m. Adjourn for noon checkout

\section{Results}

The leadership emerged from the retreat with ideas for events for the coming year, a plan to create a new student-led advisory board for the library, a marketing plan that would improve relationships with campus faculty and administration, and an assessment plan that highlighted connecting our metrics more directly to the library's decision making.

Following the retreat, one of the librarians who had been tasked as the recorder produced two reports. One was an exhaustive series of notes and photos that documented the entirety of the retreat, and the other was an executive summary designed to be shared with the campus leadership. Response from the 
campus leaders was uniformly positive and indicated eagerness to see the outcomes of the work in the coming year.

All action items were added to the agenda of the regular library leadership meeting and were revisited every week at the library team meeting. This gave the team leaders continued ownership of their action items, but also created a sense of accountability. Lastly, with the leadership team invested in each action item and its success, the weekly leadership meetings provided the necessary support to follow through and accomplish each item.

The costs for the two-day leadership retreat were minimal. The facility was a vacation rental home secured through the VBRO web site for a total of $\$ 700.00$. Each librarian took responsibility for one meal, and everyone brought snacks and drinks to share with the group; as a result, there were no costs for food or catering, and everyone seemed to really enjoy the opportunity to share their favorite recipes with the team. Lastly, since each team leader developed their own interactive approach to building the plan, no consultants were required. With the inclusion of travel, the overall cost of the retreat was less than $\$ 800.00$, a $70 \%$ reduction in cost.

Owing to the success of the first retreat, a second one-day follow-up retreat was conducted six months later. The purpose of this retreat was somewhat different, with a focus on two specific library-related programs, but it also gave the group a chance to review and revisit the plan and the action items and to see if assessment data had begun to shift. Although the correction at six months was minor, the data clearly indicated improvement in all major metrics. This mid-year retreat was held at an offsite facility co-owned by the university. There were no rental or travel costs. The cost of having food brought to the retreat and a lunch at a local restaurant totaled less than $\$ 300.00$.

One year after the first retreat, the library plan remains in place and all action items have been either resolved or are continuing. Event planning continues throughout the year, and library visibility on campus has improved. Library gate count has improved modestly, by an overall rate of about $8 \%$. Mediated searching has plateaued and is at the same level as last year; however, library instruction counts have improved considerably, with the overall number of instruction participants up by $46 \%$ from the previous year. In order to continue the good work being done, the library just hosted another leadership retreat to lay out plans for the coming year. The structure was similar to last year's retreat, and the cost was around $\$ 800.00$.

\section{Discussion and Conclusions}

While lacking the often somber and authoritarian tones of a formal strategic planning effort, the use of retreats to conduct planning seems to be an acceptable means to get the right people in a room together to try to make better decisions. Some factors should be considered, however. 


\section{Teamwork}

The library leadership team in this case study has a history of collegiality, teamwork, informality, and supporting one another's goals. Their cohesiveness was a significant factor in being able to engage in the retreat together: no one member of the leadership team came to the retreat with their own agenda, only that of the library as an institution. With a less cohesive team, a retreat might need to include team-building exercises prior to engaging in planning.

\section{Size}

Only six librarians make up the leadership team at the OU-Tulsa Schusterman Library. This team structure has the advantage of being small and mostly lateral in structure, avoiding the pitfalls of having to speak truth to power in a large group setting. With a small team, everyone gets a chance to speak and to be heard. Larger groups sometimes stifle individual voices.

\section{Shared Costs}

Although the major costs of managing a retreat like the one described here are vacation home rental (between $\$ 500.00$ and $\$ 800.00$ for a two-night stay) and travel (approximately $\$ 100.00$ in mileage or van rental), all of the participants are sharing other costs for food and beverages. Again, with a smaller team that has strong cohesion, this is not an issue, but a larger group is more expensive to feed, and sharing those costs might create some resentment. A modest grocery allowance might offset those costs and keep the team from developing hard feelings.

\section{Consultants}

Although in this example no paid consultants were used, having an outside expert lead the discussion can defuse potential friction among participants and can provide stability and direction to the work being accomplished. For groups that lack the financial resources to hire an outside consultant, one suggestion might be to look for other professionals in one's field who have the interest and are willing to assist the planning work pro bono. As an example, seeking out another academic library director to manage our retreats might have been a possibility.

\section{Continuity}

Part of the success of this planning effort can be directly attributed to the weekly leadership meetings and the team's ability to continue the work from the retreat. Resources need to be provided to make the plans become a reality, and that means that the leadership must back the plans from the retreat with both time and money. Coming out of a planning retreat, everyone should know who is going to do the work needed and how that work will be supported by the administration. 


\section{Conclusion}

Staying ahead of the pitch is an old baseball metaphor that means to anticipate where the ball is going to go so that the batter can score a hit. But to anticipate changes in a field as robust and challenging as information sciences, reflection and contemplation are often key to good planning. With simple day-today management of libraries already being a full-time task, true leadership and planning often comes with a real, physical break from the workplace and daily routines. With this in mind, the leadership retreat should be employed by librarians to give themselves the luxury of deep reflection, camaraderie, and thoughtful planning in environments conducive to such work.

The work of a planning retreat is done before the retreat, during the retreat, and after the retreat. The planning might find focus for a few days in a peaceful vacation setting, but the work of planning is a constant, and the support for this work must be as steadfast. High-paid consultants are not needed for good planning, but a smart team that works well together most certainly is. Committing to a plan can lead to real progress in an organization, and if a retreat can be carried out at a reasonable cost, it can lead to exceptional outcomes.

\section{References}

Casey, A. M. (2015). Grassroots strategic planning: Involving library staff from the beginning. Journal of Library Administration, 55(4), 329-340. doi:10.1080/01930826.2015.1038935

Cluff, E. D., \& Von Dran, G. M. (1988). Staff retreats in ACRL libraries. College \& Research Libraries News $8,517$.

Dobb, L. S. (1999). Four retreats and a forum: A meditation on retreats as a response to change. Library Trends, 47(4), 699-710.

Gray, S. A., Brower, S., \& Munger, H. (2001). Redefining reference in an academic health sciences library: Planning for change. Medical Reference Services Quarterly, 20(3), 1-11. doi:10.1300/J115v20n03_01

Kirkland, J., \& Dobb, L. S. (1989). The retreat as a response to change. Library Trends, 37, 495-509.

Matthews, J. R. (2005). Strategic planning and management for library managers. Westport, CT: Libraries Unlimited. 